\title{
Effects of calcium cyanamide on Collembola in a standardized field test: Part 1. Rationale and performance of the study
}

\author{
Petra Stegger $^{1 *} \mathbb{D}$, Jörg Römbke ${ }^{2}$, Jörg-Alfred Salamon ${ }^{3}$ and Klaus Peter Ebke ${ }^{1}$
}

\begin{abstract}
Background: A field study lasting one year was performed to study the effects of a calcium cyanamide fertiliser (trade name: Perlka ${ }^{\circledR}$ ) on Collembola in order to support the terrestrial risk assessment under the REACH (Registration, Evaluation, Authorisation and Restriction of Chemicals) regulation. Due to the lack of an appropriate guidance document, the design of the study was based on the ISO Guideline 11268-3, originally developed for earthworm field studies. However, the sampling procedure was adapted accordingly by applying ISO Guideline 23611-2, i.e. taking soil core and pitfall trap samples. Two groups of four plots each were treated with $200 \mathrm{~kg} / \mathrm{ha}$ and $400 \mathrm{~kg} / \mathrm{ha} \mathrm{Perlka}{ }^{\circledR}$, respectively. A third group served as a fertiliser control, i.e. it was treated with a standard urea fertiliser $(172.9 \mathrm{~kg}$ Piagran ${ }^{\circledR} / \mathrm{ha}$ ) at the same total nitrogen rate $(79.5 \mathrm{~kg} / \mathrm{ha})$ as provided by the high Perlka ${ }^{\circledR}$ application rate. The fourth group served as negative control without any fertiliser treatment and the fifth group was treated with the reference item Agriclor $^{\circledR}$ (480 $\mathrm{g}$ a.i./L chlorpyrifos), known to be toxic to springtails.

Results: In total 16 different Collembola species were determined. For seven species, covering all life form types, a reliable statistical evaluation was possible, which was reflected in correspondingly low MDD values in the study. A statistically significant decrease of the abundance (at least 50\%) on the reference item plots compared to the untreated control was observed for six species, thus demonstrating the sensitivity of the Collembola community.

Conclusion: No long-lasting effects of the Perlka ${ }^{\circledR}$ application rates could be observed for any of the Collembola species. In order to support risk assessors in both industry and authorities in the interpretation of large and complex data sets typical for field studies with chemicals, further guidance on implementation and data interpretation is urgently needed.
\end{abstract}

Keywords: Springtails, Terrestrial risk assessment, Perlka ${ }^{\circledR}$, Realistic exposure, MDD, REACH

\section{Background}

According to REACH regulation, toxicity data from soil invertebrates for terrestrial risk assessment are mandatory for high tonnage products such as mineral fertilisers that are applied directly to the soil, i.e. standard laboratory tests with soil invertebrates must be performed.

\footnotetext{
*Correspondence: petra.stegger@mesocosm.de

1 Mesocosm GmbH, Forschungszentrum Neu-Ulrichstein, Neu-Ulrichstein

5, 35315 Homberg(Ohm), Germany

Full list of author information is available at the end of the article
}

For the terrestrial risk assessment of calcium cyanamide as a fertiliser (trade name: Perlka ${ }^{\circledR}$ ) under REACH, the evaluating authorities used a read-across approach for the first transformation product in soil, cyanamide. Thereby, as a result of a standard laboratory test according to OECD 232 [1, 2], Folsomia candida was identified as the most sensitive soil invertebrate species, so that a risk for the soil compartment could not be excluded. As the conditions of the use of calcium cyanamide as fertiliser are completely different from the standard test conditions, i.e. granules versus solution as test item, pulse disturbance versus continuous exposure, a field study 
was initiated by the registrant to examine the effects of calcium cyanamide on Collembola under realistic conditions over a period of one year.

For Collembola field tests no specific guidance document is available so far. However, several times such field tests have been recommended by experts from industry, agencies and academia, mostly in order to evaluate the effects of pesticides on Collembola [e.g., 3, 4]. Based on these recommendations, the study was designed using the standard earthworm field test guideline ISO 11268-3 (ISO 2014) [5] as a template-a procedure regularly used by ecotoxicological laboratories conducting field studies that is accepted in pesticide registration dossiers [e.g., 6].

The aim of the current study was to investigate possible adverse effects of the mineral fertiliser Perlka ${ }^{\circledR}$, containing $45 \%$ of calcium cyanamide, on the abundance and activity density of natural Collembola populations in the field by conducting a one-year field study. Since Collembola are involved in the decomposition and mineralization processes of the soil [7-10], indirect effects on the Collembola community can be hypothesized to be mediated, e.g., by increased plant growth from the use of chemical fertilisers. Therefore, the design comprised five treatment groups: two groups of plots were treated with $200 \mathrm{~kg} / \mathrm{ha}$ and $400 \mathrm{~kg} / \mathrm{ha}$ Perlka ${ }^{\circledR}$, respectively. The third group served as fertiliser control, treated with a standard urea fertiliser at the same total nitrogen rate as provided by the high Perlka ${ }^{\circledR}$ application rate. The fourth group served as negative control without any fertiliser treatment and the fifth group was treated with the reference item Agriclor ( $480 \mathrm{~g} / \mathrm{L}$ chlorpyrifos). A meadow was selected as model system due to its diverse and abundant soil fauna community resulting from a lack of soil disturbance [11], thus enabling the study to cover a wide range of taxa, with sufficient numbers of individuals to allow a meaningful statistical analysis.

This paper presents the implementation and results of a Collembola field study with a mineral fertiliser. In addition, the difficulties in using such complex data sets for the environmental risk assessment of chemicals under REACH will be discussed. A detailed proposal for the evaluation of the outcome of this (and comparable) studies will be presented in the second part of this publication.

\section{Material and methods}

The study was conducted under GLP conditions. The test field was a meadow near Homberg $(\mathrm{Ohm})$ at the FNU research centre Neu-Ulrichstein, Hesse, Germany. Since 2010 it was used as meadow without the use of mineral fertilisers and pesticides. For the characterization of the field the soil particle size distribution, organic matter content of the soil, soil $\mathrm{pH}$, total $\mathrm{N}$-content and water holding capacity of the A-horizon was determined from samples taken at $0-30 \mathrm{~cm}$ depth once on 18 September 2018 in every quadrant of the experimental field using a Puerkhauer sampler. On each sampling date, vegetation height and coverage of the plots for each treatment group was recorded. On the dates of soil core sampling, soil moisture was determined using a Theta-Probe (HH2 meter, Delta-T Devices, Cambridge, UK). Continuous weather data (air temperature, precipitation and soil temperature) during the study period were obtained from the DWD (Deutscher Wetter Dienst) weather station (World Meteorological Organization number 10537) about $500 \mathrm{~m}$ away from the test field. Climatic conditions (air temperature, air humidity, soil temperature and on date of application wind velocity) on the experimental field were recorded with suitable instruments (ALMEMO type $2290-8$ or 2590; AHLBORN Mess-und Regelungstechnik GmbH, 83,602 Holzkirchen, Germany) on the date of application and each sampling date.

\section{Test design and test item/reference item application}

The test was designed according to ISO 11268-3 [5] with five treatments and four replicates each (20 plots in total) as a randomized block design. The plot size was $10 \times 12 \mathrm{~m}\left(120 \mathrm{~m}^{2}\right)$ with a distance of at least $3 \mathrm{~m}$ between adjacent plots and a plot margin (unused) of at least $10 \mathrm{~m}$. Four plots were left untreated as unfertilized control. Four plots were treated with $200 \mathrm{~kg}$ Perlka ${ }^{\circledR /}$ ha and $400 \mathrm{~kg}$ Perlka ${ }^{\circledR} / \mathrm{ha}$, respectively. The urea fertiliser Piagran ${ }^{\circledR} 46$ (SKW Piesteritz, total nitrogen content approx. $46.5 \%$ (nominal)) was applied to four plots at the same total nitrogen rate as provided by the high Perlka ${ }^{\circledR}$ application rate, corresponding to $172.9 \mathrm{~kg}$ Piagran ${ }^{\circledR} / \mathrm{ha}$. As reference item Agriclor $^{\circledR}$ (480 g chlorpyrifos/L) was used at a rate of $1.449 \mathrm{~L}$ product/ha (corresponding to $0.72 \mathrm{~kg}$. chlorpyrifos $/ \mathrm{ha}$ ) in $400 \mathrm{~L}$ water $/ \mathrm{ha}$. The reference item was applied once with the first application of the mineral fertilisers. The first application of Perlka ${ }^{\circledR}$ (batchno.: SWSE-18-068; content of a.i.: $45.0 \%$ calcium cyanamide (analysed)), Piagran ${ }^{\circledR}$ and the reference item was on 28 September 2018. The second application of Perlka ${ }^{\circledR}$ (batch-no.: SWSE-19-017; content of a.i.: 44.4\% calcium cyanamide (analysed)) and Piagran ${ }^{\circledR}$ was on 2 April 2019.

The mineral fertilisers were applied using an accurate fertiliser spreader for granules (Hege 80 Parzellenstreuer, System Weihenstephan, Model 422437 with a working width of $1.50 \mathrm{~m}$ and 10 gape pipes, Hans-Ulrich Hege Saatzuchtmaschinen, 74638 Waldenburg, Germany). For the application of the reference item a movable plot sprayer for field application; type PSG 4 FE (Fa. Schachtner Gerätetechnik, 71640 Ludwigsburg, Germany) was used, with an extension tube including 5 spraying nozzles (Lechler IDK 120-04; distance between 
nozzles: $50 \mathrm{~cm}$ ) operating with compressed air and a boom width of $250 \mathrm{~cm}$ and a distance to soil of approximately $50 \mathrm{~cm}$. Since Perlka ${ }^{\circledR}$ and Piagran ${ }^{\circledR}$ are formulated as granules, verification of the application rate cannot be carried out in the same way as for plant protection products, where overspray of soil samples or filter material in Petri dishes is the recommended method for quantifying the applied amount of test item [3]. Therefore, a method according to DIN 13739-1 [12] was used to verify the applied quantity and distribution homogeneity. Five collecting trays $(37.5 \times 50 \mathrm{~cm})$ were placed on each Perlka ${ }^{\circledR}$ and control fertiliser plot. The trays were passed once during the application. Weight of the granules in the trays was determined. The amount of granules applied per hectare was calculated on the basis of the surface area of the collection trays and the amount of fertiliser collected.

After the first application, the test field was irrigated to achieve at least $10 \mathrm{~mm}$ precipitation. After the second application, sufficient natural rainfall occurred. Due to a summer characterized by high temperatures and long periods of drought, irrigation was carried out before the start of the study to achieve appropriate sampling conditions $\left(11 \mathrm{~mm} / \mathrm{m}^{2}\right.$ on 30 August, 31 August, 3 September, 4. September and 13 September 2018, respectively, in total $55 \mathrm{~mm} / \mathrm{m}^{2}$ ). In preparation of the autumn samplings in 2019 the following irrigation schedule was implemented: 3 September 20197 L/m², 4 September 20198 $\mathrm{L} / \mathrm{m}^{2}$, 10 September $20198 \mathrm{~L} / \mathrm{m}^{2}$, 11 September 20199.6 $\mathrm{L} / \mathrm{m}^{2}, 12$ September $201910 \mathrm{~L} / \mathrm{m}^{2}$.

\section{Sampling and identification of Collembola}

Collembola were sampled by collecting 6 soil cores per plot with a depth of $5 \mathrm{~cm}$ using a core sampler with $5 \mathrm{~cm}$ diameter followed by heat extraction with a modified MacFadyen extraction apparatus according to ISO 23611-2 [13]. Soil core samples were taken on 11 sampling dates: 26 September 2018; 2 October 2018; 12 October 2018; 26 October 2018; 1 April 2019; 5 April 2019; 16 April 2019; 30 April 2019; 24 June 2019; 23 September 2019 and 15 October 2019. The specimens were identified at species level and the number per soil core was determined.

In addition, four funnel pitfall traps according to Barber and Melber $[14,15]$ were installed in the central area of each plot with at a distance of $2 \mathrm{~m}$ from each other. The traps were opened for 4 days at each sampling and were equipped with a preservative $(50 \%$ ethylene glycol, $50 \%$ water) in order to conserve the captured organisms. The samples were taken on 11 occasions: 25 September 2018; 5 October 2018; 12 October 2018; 26 October 2018; 1 April 2019; 8 April 2019; 16 April 2019; 30 April 2019; 24 June 2019; 23 September 2019 and 15 October 2019. After sampling the pitfall trap specimen were washed with tap water to remove soil and plant material; washing water was poured through sieves with a mesh size of $150 \mu \mathrm{m}$ and the samples were fixed with $70 \%$ ethanol until the taxonomic evaluation was performed. The specimens were identified at species level and the number of individuals per trap for each species was determined.

Taxonomic identification was carried out using a dissecting microscope and/or transmitted light microscope and the following keys [16-26].

\section{Data evaluation}

For the statistical evaluation the results of both sampling types were considered individually.

To test the significance of the differences between the mean values of controls and treatments for each taxon and sampling date, the multiple t-test by Williams [27, $28]$ was used, which provides the NOER (No Observed Effect Rate) at the population level ( $\alpha=0.05$, one-sided). For regulatory purposes direct effects are in the focus, expecting monotonic concentration-responses of the test item. Therefore, Williams test was selected for the evaluation. Furthermore, one-sided tests were selected to increase the power of the test to detect direct effects with a monotonous dose-response. Direction of the test was determined from comparison of the means of controls and highest treatment level. If for example the mean abundance at the highest test concentration was lower than the mean of the control, the test was conducted for a decrease of abundance, and vice versa.

The minimal detectable difference (MDD) at the NOER in accordance with Brock et al. [29] was also calculated as an indication of the statistical power. For NOER-calculation abundance data of the taxa were log transformed $\left[y^{\prime}=\ln (a y+1)\right]$ with $a=2 / \min (x)$ before analysis in order to better approximate normality and homoscedasticity (homogeneity of variances) requirements, whereby $\min (x)$ was the smallest value of the data set, which was greater than zero [30]. NOER-calculations were done with the program Community Analysis (CA) 4.3.14 [31].

As some statistically significant differences could be determined between the control and the fertiliser control, the statistical evaluation of the effects of the Perlka ${ }^{\circledR}$ application rates were done separately in comparison with the untreated control and the fertiliser control.

Number of species, Shannon Index and evenness were used to describe the diversity of the community. Shannon Index, a diversity measure depending on species richness and frequency distribution of the individuals of the species, was calculated using the following formula:

$$
H_{\mathrm{S}}=-\sum p_{j} \ln \left(p_{j}\right)
$$


with $H_{\mathrm{S}}=$ Shannon Index, $p_{j}=$ relative abundance of species $j$.

Evenness was calculated as follows: $E=H_{\mathrm{S}} / H_{\mathrm{S} \max }=H_{\mathrm{S}} /$ $\ln (n)$, with $E=$ evenness, $n=$ number of species.

To determine differences between the means in controls and treatment the multiple t-test by Williams [27, 28] of the program Community Analysis (CA. 4.3.14) was used.

In order to evaluate the validity of the study, the comparison of control and reference item was done separately. Abundance of Collembola was tested for normality (Shapiro-Wilk test) [32] and homogeneity of variance (Levene's test) $[33,34]$ using ToxRat ${ }^{\circledR}$ Professional (ToxRat ${ }^{\circledR}$ Solutions GmbH, 52477 Alsdorf, Germany, Version 3.3.0). Depending on the results, Student's t-test, Welch t-test or Mann-Whitney U-test was selected to compare control and reference item. These tests were calculated one-sided smaller $(\alpha=0.05)$. The comparison of the untreated control and fertiliser control was evaluated in the same way, but the respective tests were calculated two-sided $(\alpha=0.05)$. According to de Jong et al. [3], only taxa with a mean abundance of $>2.5$ individuals per sample in the control were considered relevant for the statistical evaluation.

\section{Results}

\section{Test system}

The test field was characterized as follows: soil type, silt loam (US Department of Agriculture, USDA); total organic carbon 2.56-2.64\%; lime content $<0.1 \%$; $\mathrm{pH}$ 5.34-5.50; water holding capacity $58.0-57.5 \%$, nitrogen $0.28-0.29 \% \mathrm{~N}$.

The vegetation height at the samplings from autumn 2018 up to 8 April 2019 was in the range of 6-10 cm. Until sampling on 24 June 2019, the vegetation height increased to $76-94 \mathrm{~cm}$. After harvesting on 2 July 2019, the vegetation height for the two sampling dates in autumn 2019 was in the range of $16-20 \mathrm{~cm}$. The amount of grass biomass collected from the plots was: $44 \mathrm{~kg} / \mathrm{plot}$ (reference item), $40 \mathrm{~kg} /$ plot (untreated control), $84 \mathrm{~kg} /$ plot (fertiliser control), $67 \mathrm{~kg} /$ plot (200 kg Perlka ${ }^{\circledR} / \mathrm{ha}$ ) and $86 \mathrm{~kg} /$ plot (400 kg Perlka $\left.{ }^{\circledR} / \mathrm{ha}\right)$. Harvest was necessary to avoid too thick layers of mulch, which might have suffocated soil life. On the days of soil core sampling, soil moisture on the different treatment plots did not show any statistically significant difference. The following mean values were determined considering all plots from the first to the last soil core sampling date: 29.0, 31.1, $21.3,19.1,28.1,41.0,18.2,29.5,20.4,23.8$ and $36.5 \%$. In general, the weather during the study period was characterized by long periods of drought, interrupted by heavy rainfalls. The annual precipitation in both years was clearly below the long-term average of the last 20 years (2018 for 24\%, 2019 for 29\%) (Fig. 1).

\section{Application}

The first application was done on 28 September 2018. Weather conditions were as follows: Temperature was in the range of 9 to $14{ }^{\circ} \mathrm{C}$, no precipitation, cloudy. As there was no rainfall within 3 days after application on 1 October 2018, all plots were artificially irrigated with $10 \mathrm{~mm}$ $\left(10 \mathrm{~L} / \mathrm{m}^{2}\right)$. The second application was done on 2 April 2019. Weather conditions were as follows: Temperature was between 6 and $16{ }^{\circ} \mathrm{C}$, no precipitation, sunny with some clouds towards the end of the application. As sufficient rain $\left(10 \mathrm{~L} / \mathrm{m}^{2}\right)$ fell within 3 days of application, no artificial irrigation was necessary.

Exposure of the test item was confirmed for both application dates by negligible residue amounts of up to $0.4 \%$ of the respective application rate in the fertiliser spreader and by a generally "very good" to "good" CV (coefficient of variation) for the variability of distribution according to DIN 13-739-1 [12] (Table 1). Therefore, evaluation of the results was done using the nominal test item rate. The application of the reference item parallel to the first application of fertiliser was confirmed by a small deviation between 1.5 to $2.3 \%$ from the target quantity read on the validated flow meter of the movable plot sprayer.

\section{Effects on Collembola Validity}

Total abundance of Collembola was statistically significantly reduced by at least $50 \%$ in the reference item compared to the untreated control in pitfall trap and soil core samples on each of the three post-application sampling dates after the first application. In addition, for six of the eight species (75\%) found in pitfall trap and soil core samples, for which an evaluation was reliable, a statistically significant decrease in abundance by more than $50 \%$ compared to the untreated control could be observed on the first three post-application sampling dates, demonstrating the sensitivity of the test system. Therefore, the evaluation of the samples taken from reference replicates at later samplings dates was waived. Additionally, the reference item was compared with the fertiliser control showing that the validity criterion was also fulfilled for the comparison of the reference item with the fertiliser control.

\section{Collembola data in pitfall trap samples}

In the pitfall trap samples in total 12 different species were identified (without juveniles). Eight of these were present in the replicates of the untreated control and 10 species were found in the replicates of the fertiliser control. The control samples were dominated by 
25

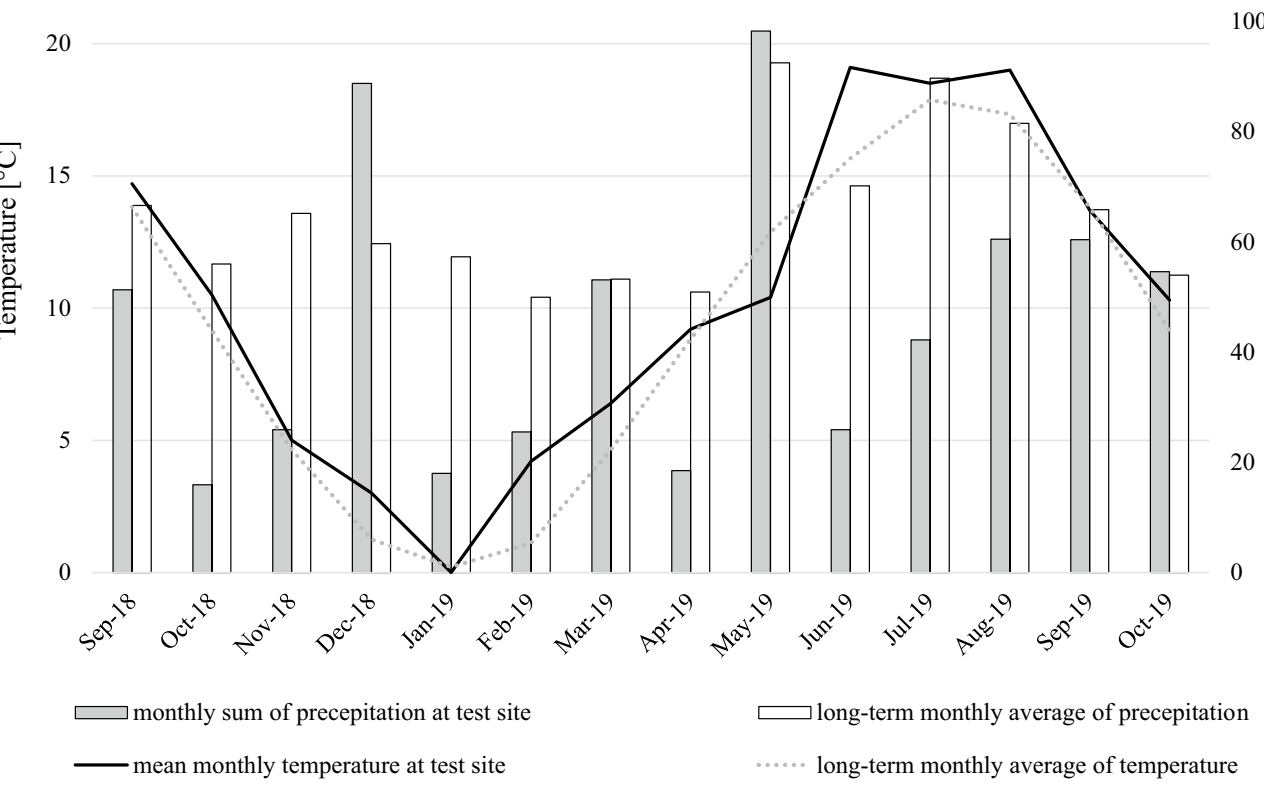

20
120

100

छ

Fig. 1 Climatic conditions (1999-2017) in comparison to study period in 2018 and 2019

Table 1 Mean application rate and variability of distribution for Perlka ${ }^{\circledR}$ and Piagran ${ }^{\circledR}$ on the first and second application date

\begin{tabular}{|c|c|c|c|c|c|c|c|}
\hline \multirow{2}{*}{\multicolumn{2}{|c|}{$\begin{array}{l}\text { Appl. rate } \\
\text { Application }\end{array}$}} & \multicolumn{2}{|c|}{200 kg Perlka ${ }^{\circledR} /$ ha } & \multicolumn{2}{|c|}{400 kg Perlka ${ }^{\circledR} /$ ha } & \multicolumn{2}{|c|}{172.9 kg Piagran ${ }^{\circledR} / \mathrm{ha}$} \\
\hline & & \multirow{2}{*}{$\begin{array}{l}\text { 1st } \\
\text { Mean }\end{array}$} & \multirow{2}{*}{$\begin{array}{l}\text { 2nd } \\
\text { Mean }\end{array}$} & \multirow{2}{*}{$\begin{array}{l}\text { 1st } \\
\text { Mean }\end{array}$} & \multirow{2}{*}{$\begin{array}{l}\text { 2nd } \\
\text { Mean }\end{array}$} & \multirow{2}{*}{$\begin{array}{l}\text { 1st } \\
\text { Mean }\end{array}$} & \multirow{2}{*}{$\begin{array}{l}\text { 2nd } \\
\text { Mean) }\end{array}$} \\
\hline Plot & Parameter & & & & & & \\
\hline \multirow[t]{2}{*}{1} & A & $3.99 \pm 0.2$ & $3.80 \pm 0.4$ & $8.13 \pm 0.8$ & $7.60 \pm 0.7$ & $4.11 \pm 0.9$ & $3.20 \pm 0.2$ \\
\hline & B & $212.6(13.1 ; 6.2)$ & $203.9(23.1 ; 11.4)$ & $433.8(41.3 ; 9.5)$ & $407.3(38.5 ; 9.5)$ & $219.4(46.3 ; 21.1)$ & $169.0(9.1 ; 5.4)$ \\
\hline \multirow[t]{2}{*}{2} & A & $3.65 \pm 0.3$ & $3.80 \pm 0.4$ & $7.77 \pm 0.6$ & $7.7 \pm 0.7$ & $3.26 \pm 0.6$ & $3.20 \pm 0.2$ \\
\hline & B & $194.7(18.7 ; 9.6)$ & $204.6(18.9 ; 9.2)$ & $414.6(32.9 ; 7.9)$ & $412.6(36.5 ; 8.8)$ & $173.9(30.8 ; 17.7)$ & $169.4(11.3 ; 6.7)$ \\
\hline \multirow[t]{2}{*}{3} & A & $4.31 \pm 0.6$ & $3.70 \pm 0.3$ & $7.59 \pm 0.7$ & $7.50 \pm 0.6$ & $3.57 \pm 0.8$ & $3.10 \pm 0.2$ \\
\hline & B & $229.7(33 ; 14.4)$ & $198.2(15.6 ; 7.9)$ & $404.9(39.2 ; 9.7)$ & $402.2(32 ; 8)$ & $190.5(43.6 ; 22.9)$ & $164.9(8.2 ; 5)$ \\
\hline \multirow[t]{2}{*}{4} & A & $3.52 \pm 0.3$ & $3.60 \pm 0.3$ & $8.00 \pm 0.9$ & $7.80 \pm 0.6$ & $3.72 \pm 0.8$ & $3.20 \pm 0.3$ \\
\hline & B & $187.7(16.2 ; 8.6)$ & $194.0(17.1 ; 8.8)$ & $426.9(48.9 ; 11.4)$ & $413.5(34.1 ; 8.2)$ & $198.4(40.3 ; 20.3)$ & $169.0(13.5 ; 8)$ \\
\hline
\end{tabular}

A) Content of tray, mean \pm SD [g]

B) Corresponding kg/ha, mean (SD [kg/ha]; CV [\%])

Lepidocyrtus violaceus with a dominance value of $88 \%$ of the species followed by Isotoma viridis (6\%) and Lepidocrytus lignorum (4\%).

\section{Effects on Collembola in pitfall traps}

The statistical evaluation of the abundance of Collembola in pitfall traps on the plots treated with different application rates of Perlka ${ }^{\circledR}$ compared to those found in the untreated control and the fertiliser control is presented in Tables 2 and 3.
As can be seen from the MDD values, a reliable statistical evaluation was possible for total abundance of Collembola and 5 to 3 species at the different sampling dates. When comparing the low Perlka ${ }^{\circledR}$ application rate to the untreated control, a statistically significant lower abundance could only be observed for total abundance of Collembola (Fig. 2) and Sminthurinus aureus at an isolated sampling date (day 28 after the first application). For the high Perlka ${ }^{\circledR}$ application rate compared to the untreated control, only isolated statistically 


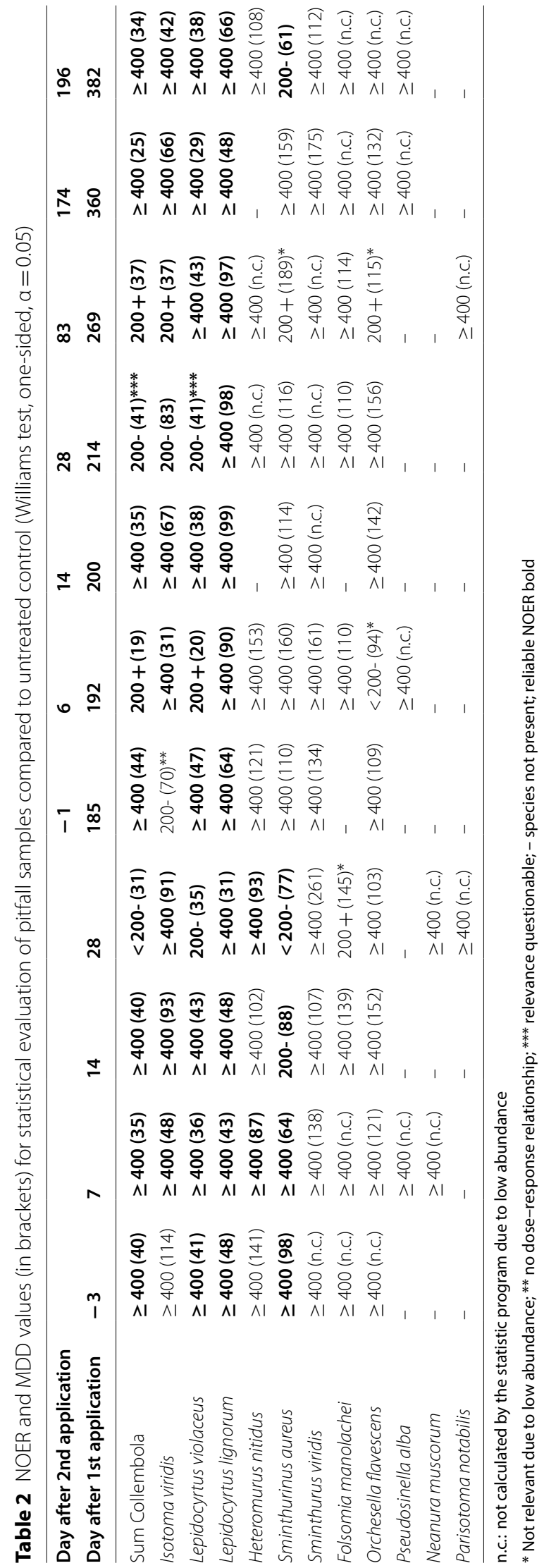




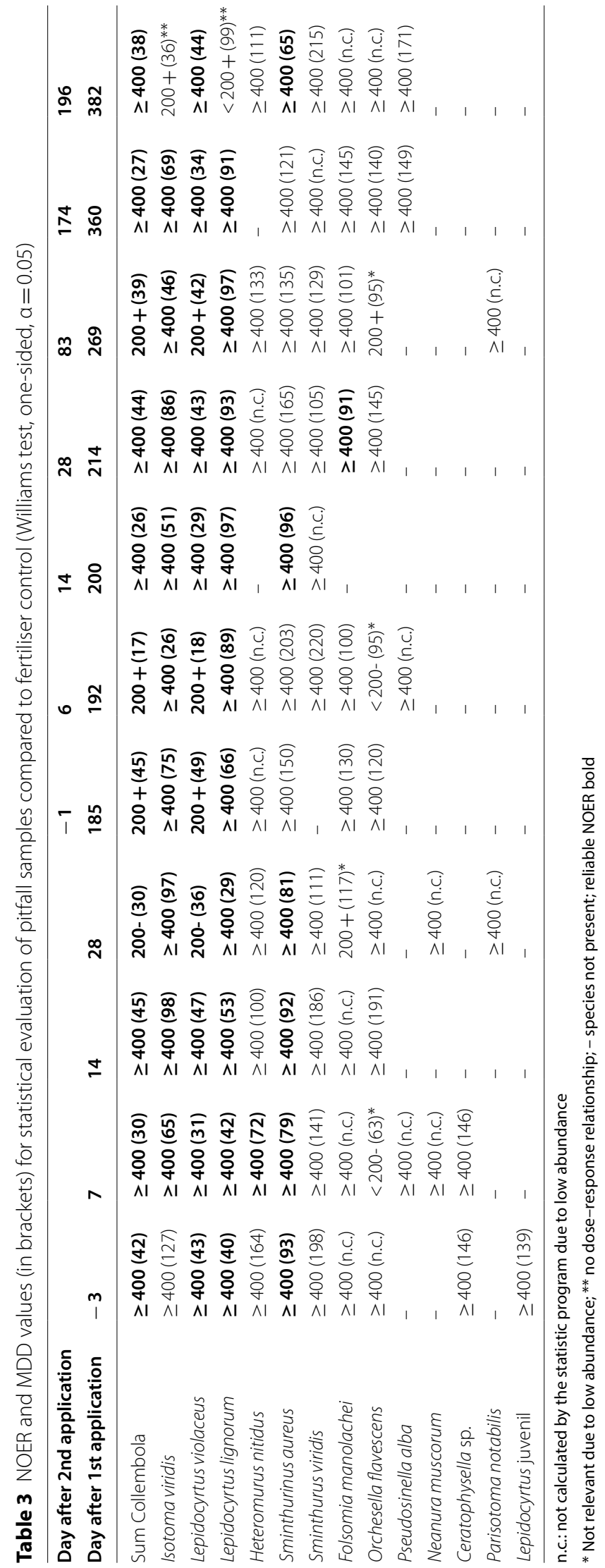




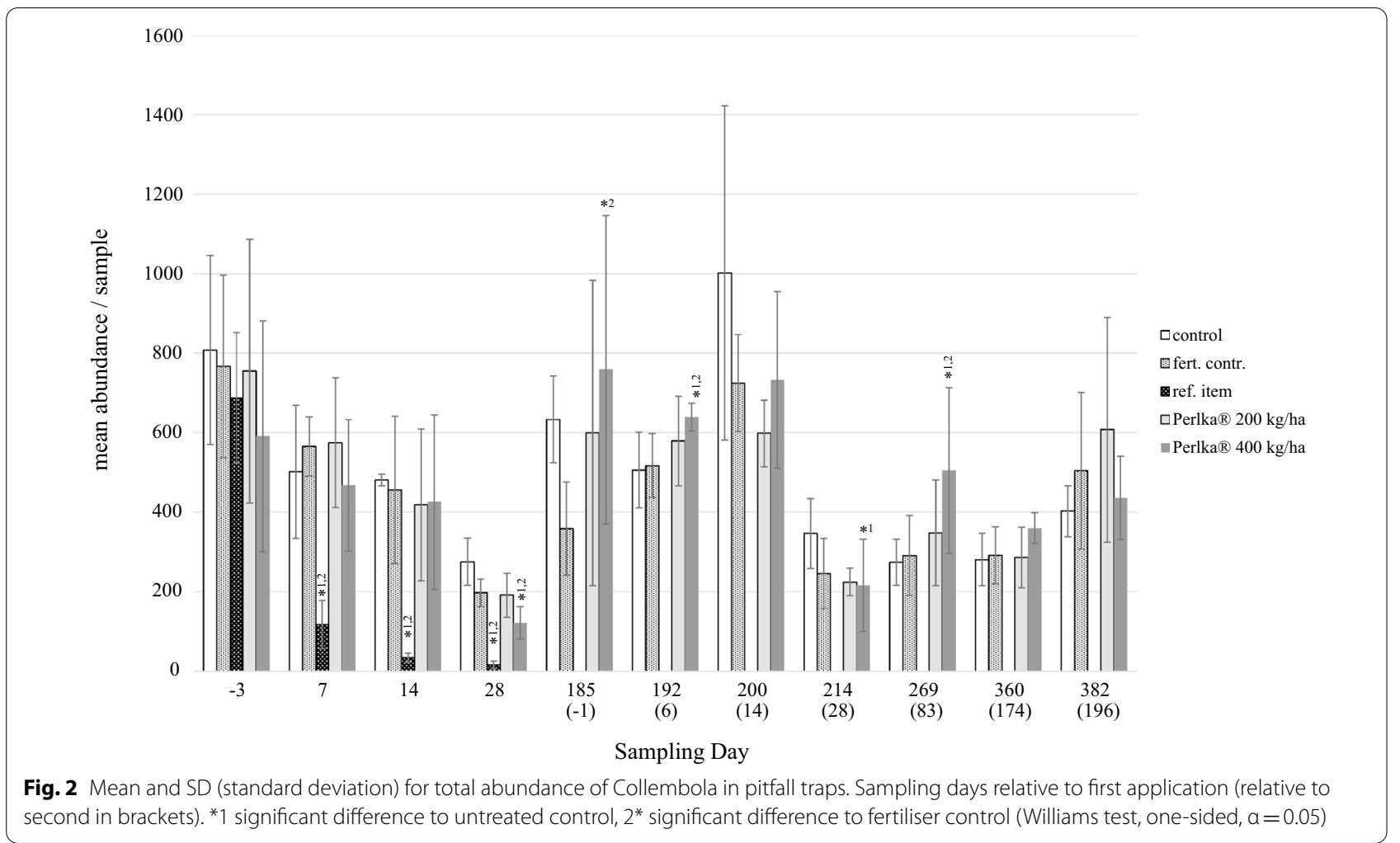

significant differences (increase as well as decrease) could be observed for the total abundance of Collembola, Isotoma viridis and Lepidocyrtus violaceus. For Sminthurinus aureus a statistically significant lower abundance could be observed on day 14 and 28 after the first application in autumn. On the following sampling dates, the abundances of $S$. aureus in the untreated control were below 2.5 individuals/sample, which according to de Jong et al. [3] is the minimum required abundance for a reliable statistical evaluation, while abundances in the test item treatments were at a higher level ( $>2.5$ individuals/sample) and even increased statistically significantly on day 83 after the second application. Based on these findings, a meanwhile recovery was assumed. Thus, the statistically significant lower abundance for the high treatment level on the last sampling date was not considered to be treatment-related. When comparing the low Perlka ${ }^{\circledR}$ application rate with the fertiliser control, no treatment-related statistically significant difference could be observed, as the statistically significant higher abundance of Lepidocyrtus lignorum on the last sampling date was caused by an unusually low value for the fertiliser control on this sampling date. For the high Perlka ${ }^{\circledR}$ application rate compared to the fertiliser control, a small statistically significant lower abundance for total abundance of Collembola and L. violaceus was observed only on day 28 after the first application, followed by statistically significant higher abundances on the following sampling dates in spring.

\section{Collembola data in soil core samples}

A total of 13 different species were determined in the soil core samples. Ten of these were present in the samples of the untreated control and 12 in the samples of the fertiliser control. Pogonognathellus flavescens only occurred on the reference item plots. The most abundant species was Lepidocyrtus violaceus with a dominance value of 54 and $52 \%$ for the untreated and fertiliser control, respectively, followed by Folsomia manolachei with 15 and 19\% and Isotoma viridis with 12 and 13\%.

\section{Effects on Collembola in soil cores}

The statistical evaluation of the abundance of Collembola in soil cores samples on the plots treated with different application rates of Perlka ${ }^{\circledR}$ compared to those found in the untreated control and the fertiliser control is presented in Tables 4 and 5.

As can be seen from the MDD values, a reliable statistical evaluation was possible for total abundance of Collembola and 5 to 7 species at the different sampling dates. For the soil cores samples in the low and high Perlka ${ }^{\circledR}$ application rates compared to the untreated control and fertiliser control, statistically significant 


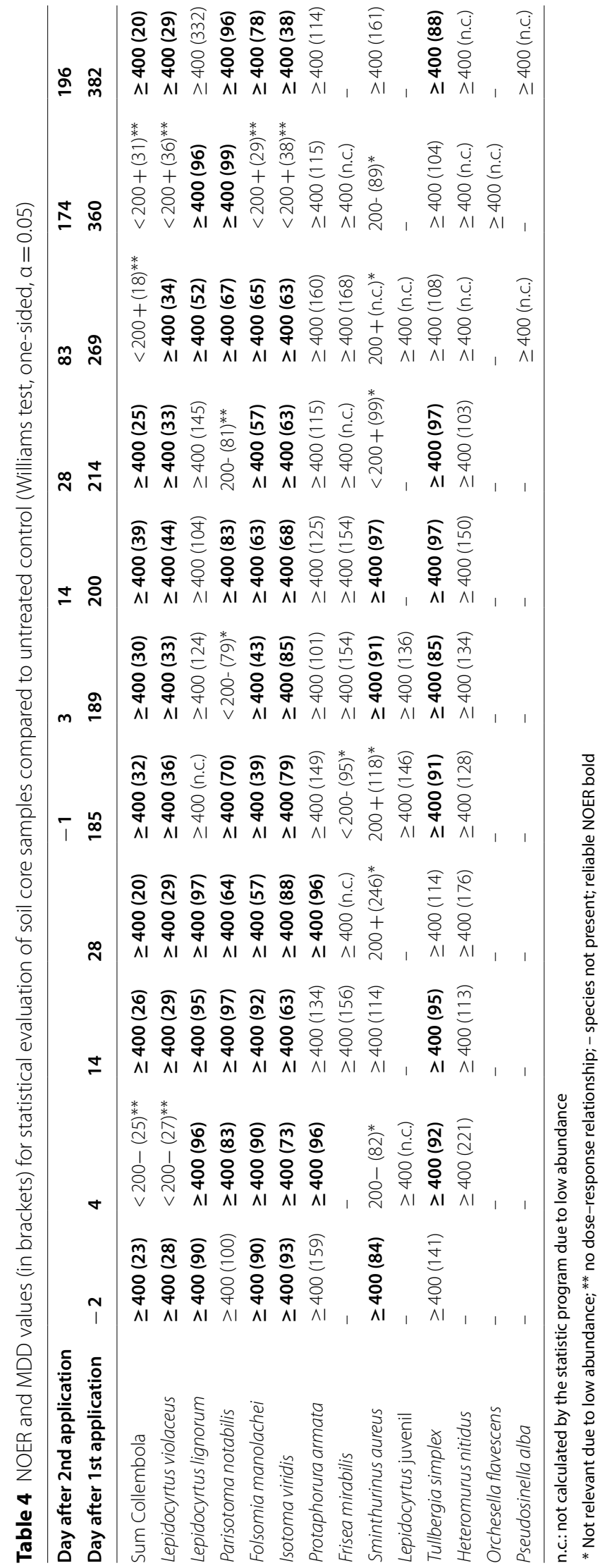




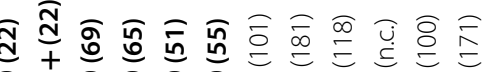

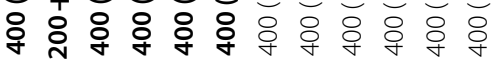

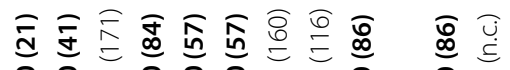

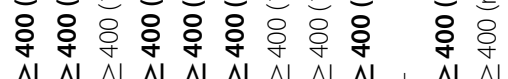
(1)

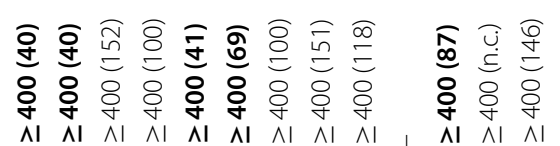

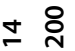

$m \stackrel{\infty}{-}$

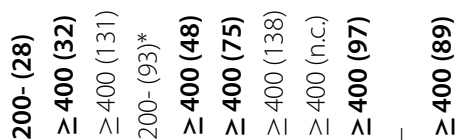

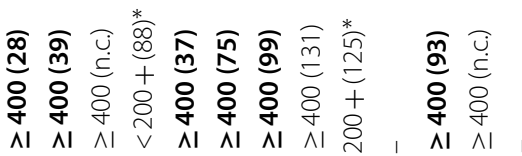

$\uparrow \stackrel{\swarrow \infty}{\infty}$

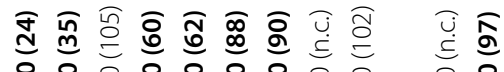

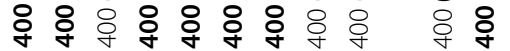

$\stackrel{\infty}{\sim}$

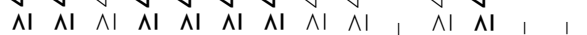

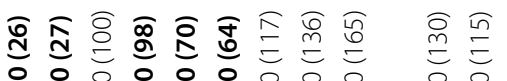

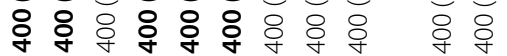

$\pm$

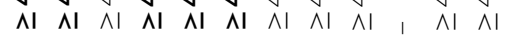

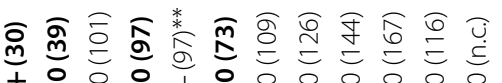

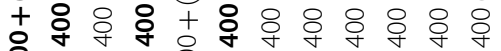

+

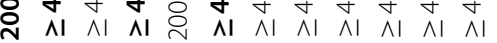

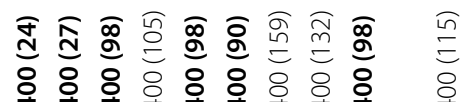

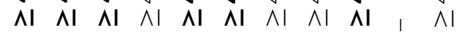
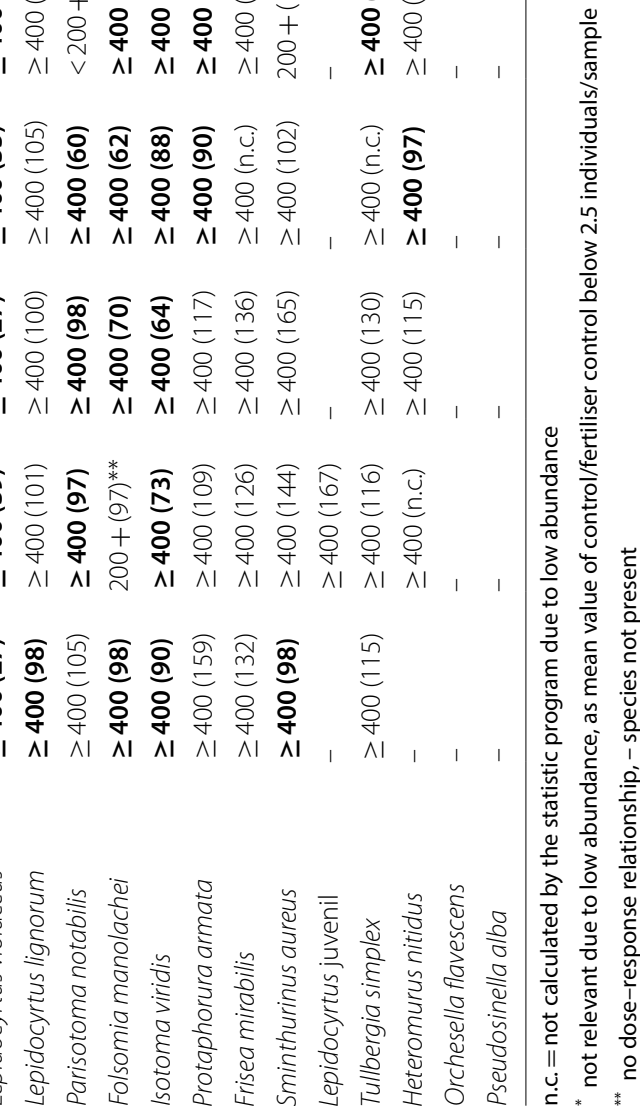
differences in both directions could only be observed on individual sampling dates, some of which even showed no dose-response relationship.

For the low Perlka ${ }^{\circledR}$ application rate in comparison to the fertiliser control, no treatment-related decrease could be observed, only a statistically significant higher abundance (29\%) of Lepidocyrtus violaceus on day 83 after the second application. For the high Perlka ${ }^{\circledR}$ application rate in comparison to the fertiliser control, also no clear treatment-related effects could be observed. On day 4 after the first application and day 3 after the second application, a statistically significant difference to the fertiliser control could be observed for the total abundance of Collembola (Fig. 3), which, however, was based once on a decrease and once on an increase. Thus, treatment relation is questionable. Due to the small effect size (28\% difference between control and treatment), the rather long time span until the last application, and the fact that no effect was observed on the previous sampling date, the statistically significant lower abundance on the last sampling date was not considered to be treatment-related.

\section{Discussion}

As no specific guidance for conducting Collembola field studies under REACH is available, the study was designed in accordance with ISO 11268-3 [5], which is the standard method for earthworm field studies to be used in pesticide risk assessment world-wide.

The design and background data collection of ISO 11268-3 [5] for earthworms can also be applied to a Collembola field study. However, the sampling procedure for earthworms is not applicable to Collembola. A specific standard, i.e. ISO 23611-2 [13], provides guidance for the sampling of Collembola, using soil core samples and pitfalls traps. Both are usual methods for Collembola sampling in soil ecology [35].

A plot size used for earthworms with a dispersal potential of 2.5 to $14 \mathrm{~m}$ per year $[36,37]$ should also be suitable for Collembola with a body size of only about $1 / 50$ to $1 / 100$ of that of earthworms. Little data are available on the dispersal potential of Collembola, mostly in terms of habitat preference or recolonization potential, showing that food resources are a strong dispersal stimulus $[38,39]$. This stimulus is not present on a meadow providing sufficient food.

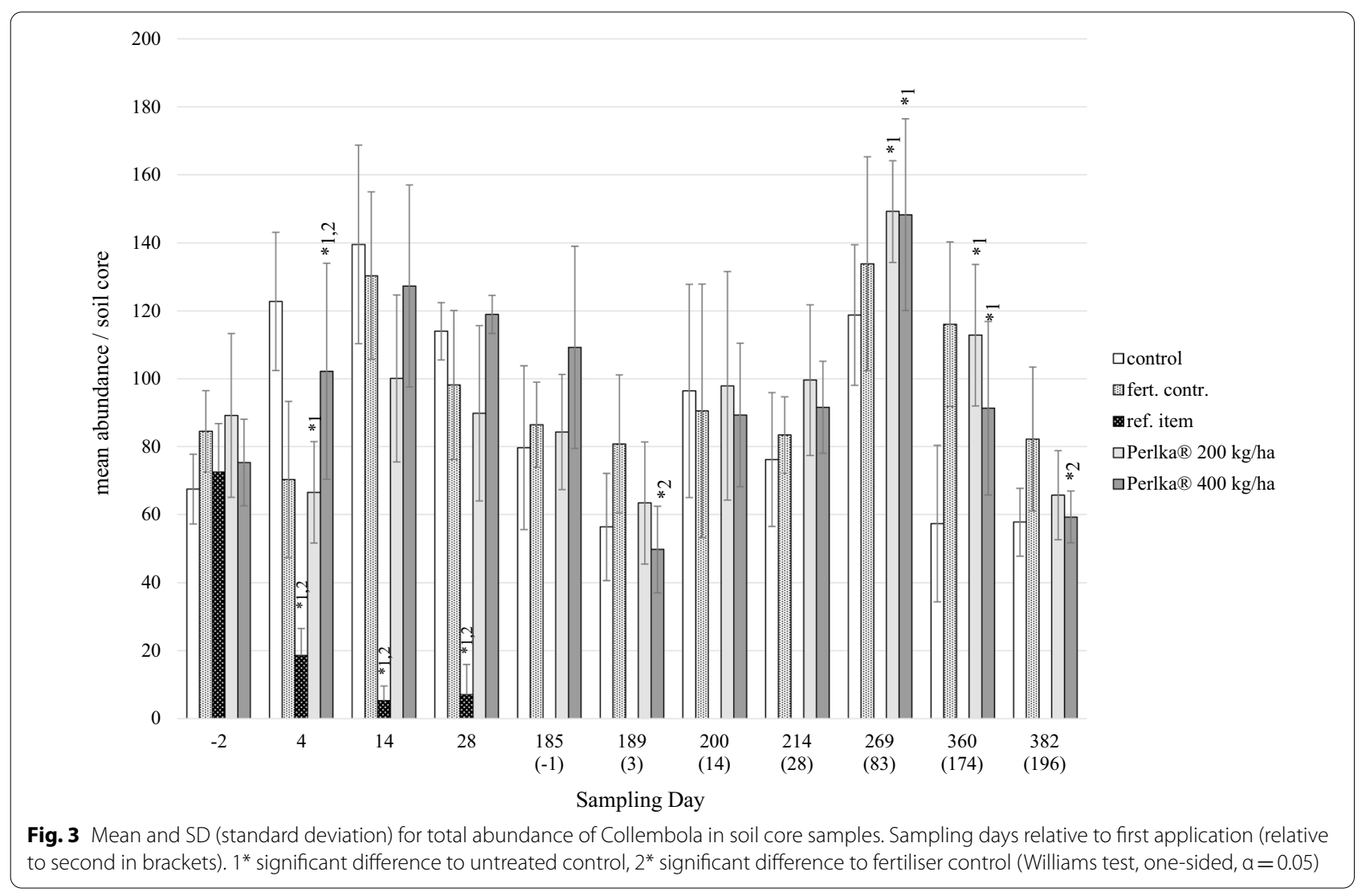


A total of 16 different Collembola species were identified in the pitfall and soil core samples. This species number is comparable to other data for grassland in Germany, where 3-21 species were observed, with a mean value of 13 species [40]. The different sampling techniques cover different life forms of Collembola. Pitfall trapping mainly target the Collembola living on the soil surface and its macrostructures or on near-ground vegetation (epedaphic). Soil core sampling focuses on Collembola living in small soil cavities (euedaphic) and in the litter layer (hemiedaphic). Therefore, high dominance values for epedaphic species like Lepidocyrtus violaceus and Isotoma viridis could be observed in the pitfall trap samples, while hemiedaphic species like Folsomia manolachei and Parisotoma notabilis or euedaphic species like Tullbergia simplex were more frequently found in soil core samples. In soil core samples abundance values of 30,000-70,000 individuals $/ \mathrm{m}^{2}$ could be observed that are clearly above average abundance values of 7900 individual $/ \mathrm{m}^{2}$ found on grassland sites in Germany [40]. Therefore, it can be assumed that the abundance in the pitfall traps is also higher compared to similar sites. As these traps focus on Collembola living on the soil surface, epedaphic species like Lepidocyrtus violaceus are likely to dominate these samples. Salamon et al. [41] investigated the Collembola fauna of grassy arable fallows of different age. The authors found out that especially Lepidocyrtus violaceus closely correlated with patches with a high soil organic matter (SOM), nitrogen and carbon content. Thus, this species presumably is able to benefit from the application of fertilisers in agricultural landscapes. High dominance values are often observed in Collembola, where the majority of individuals is represented by a small number of common species [42].

The data quality allows a reliable statistical evaluation for seven species representing all three life forms (epedaphic, hemiedaphic, euedaphic) types as discussed below. Mineral fertilisers applied directly to the soil of an agroecosystem in order to influence soil productivity are also expected to have an influence on exposed in-crop soil-dwelling organisms such as Collembola, particularly as they are supposed to play an important role in soil decomposition and nutrient mineralization processes $[43,44]$. For pesticides that are also applied to the agroecosystem in order to control pests or weeds, specific protection goals for microarthropods are currently being discussed, with definitions of acceptable magnitude of effect, time-frame of effects and recovery [45, 46]. Under $\mathrm{REACH}$, no such guidance is available for the evaluation of Collembola field tests.

For the reporting and evaluation of field tests guidance papers are available for earthworms [47] and non-target arthropods [3]. The former can be considered because the study was designed according to the ISO-guideline for earthworm field tests, and the latter because Collembola are also considered in field tests with non-target arthropods. The former focuses on the reliability of the study in terms of the integrity of reporting. It also briefly discusses the use of the results for risk assessment in terms of the acceptable magnitude of effect, the time frame and recovery processes. The latter also includes a proposal for a more detailed classification of effects. Recovery of effects is included in both guidance documents, i.e. in both cases a recovery time frame of one year is proposed. This time frame was also proposed by Candolfi et al. [48] for in-crop situations also referred to by ECHA [49] in relation to the duration of effects in field tests.

Both documents also emphasize the importance of reporting the statistical power in order to identify relevant magnitudes of effect for risk assessment. In the more recent guideline for non-target arthropods [3] the reporting of the minimum detectable difference (MDD) is highly recommended. The MDD-concept for the evaluation of treatment-related effects in experimental ecosystems, as already established for aquatic higher tier studies in pesticide regulation $[29,50]$, is also discussed as a possible concept for effect evaluation in terrestrial field studies for risk assessment of plant protection products [45]. However, recently it has been seen as premature to recommend MDD-calculations for field studies with soil organisms due to the lack of criteria to help interpret these MDD values [46]. Nevertheless, EFSA [45] defines magnitudes of effects for in-soil organisms with negligible effects up to $10 \%$, small effects above $10 \%$ and below $35 \%$, medium effects between 35 and $65 \%$ and large effects above $65 \%$. Considering that the collembolan study lasted 1 year with 10 sampling dates after the first application this frequency is comparable to a weekly sampling frequency in an aquatic study usually lasting 8 to 10 weeks after the first application. Thus, transferring these effect sizes defined by EFAS [45] to the aquatic assessment concept [29], we may analogously define a MDD Category 1 taxon if the following $\mathrm{MDD}_{\mathrm{abu}}$-values after the first application are met:

$<100-66 \%$ at no less than five samplings (large effects).

$<65-35 \%$ at no less than three samplings (medium effects).

$<34 \%$ at no less than two samplings (small effects).

Applying this evaluation to our Collembola data shows that, in addition to the total abundance, the following seven species meet the criteria of best quality as MDD category 1 taxa: Lepidocyrtus violaceus, Lepidocyrtus lignorum, Parisotoma notabilis, Folsomia manolachei, Isotoma viridis, Sminthurinus aureus and Tullbergia simplex. These species cover all life forms of Collembola that can be expected in an agricultural habitat. 
Table 6 Sum of abundance of Sminthurinus aureus in pitfall traps of all plots of the respective treatment

\begin{tabular}{|c|c|c|c|c|c|c|c|c|c|c|c|}
\hline \multicolumn{5}{|l|}{ Day after 2nd application } & \multirow{2}{*}{$\begin{array}{l}-1 \\
185\end{array}$} & \multirow{2}{*}{$\begin{array}{l}6 \\
192\end{array}$} & \multirow{2}{*}{$\begin{array}{l}14 \\
200\end{array}$} & \multirow{2}{*}{$\begin{array}{l}28 \\
214\end{array}$} & \multirow{2}{*}{$\begin{array}{l}83 \\
269\end{array}$} & \multirow{2}{*}{$\begin{array}{l}174 \\
360\end{array}$} & \multirow{2}{*}{$\begin{array}{l}196 \\
382\end{array}$} \\
\hline Day after 1 st application & -3 & 7 & 14 & 28 & & & & & & & \\
\hline Untreated Control & 186 & 348 & 195 & 159 & 26 & 12 & 30 & 24 & 4 & 17 & 215 \\
\hline Fertiliser Control & 103 & 126 & 67 & 87 & 15 & 4 & 129 & 12 & 13 & 19 & 116 \\
\hline $200 \mathrm{~kg} / \mathrm{ha}$ & 121 & 253 & 80 & $80^{*}$ & 23 & 35 & 0 & 47 & 23 & 55 & 145 \\
\hline $400 \mathrm{~kg} / \mathrm{ha}$ & 220 & 201 & $22^{*}$ & $33^{*}$ & 0 & 3 & 57 & 32 & $63^{*}$ & 49 & $64^{*}$ \\
\hline
\end{tabular}

* Statistically significant difference compared to the untreated control calculated for mean abundance values (Williams test, one-sided, $a=0.05$ )

Taking these considerations into account, it can be concluded that for both application rates of Perlka ${ }^{\circledR}(200$ and $400 \mathrm{~kg} / \mathrm{ha}$ ), generally only slight and transient effects were observed at individual sampling dates. In case effects occurred on two consecutive sampling days, they either had an opposite trend or showed an increase compared to the control.

Only for individuals of Sminthurinus aureus found in pitfall trap samples a statistically significant lower abundance for the high treatment rate compared to the untreated control could be observed on day 14 and 28 after the first application. In the further course of the study, the effect assessment for S. aureus was complicated by a generally lower abundance at the spring and summer sampling dates. A recovery in the following spring could be assumed from the summed individuals of replicates (Table 6). Furthermore, although the abundance in the untreated control was too low for a reliable statistical evaluation, abundance values of the both test item application rates were at a higher level, and on day 83 after the second application, a statistically significantly higher abundance could even be observed for the high application rate. Based on these findings, a meanwhile recovery was assumed. Thus, due to the long time interval after the last application and the fact that the sums of individuals of $S$. aureus in the test item plots were about 3 times higher than in the untreated control only 22 days before the last sampling, the statistically significant lower abundance for the high application rate on the last sampling date was not considered to be treatment-related.

\section{Conclusions and outlook}

Assessing the effects of calcium cyanamide on springtails in a field study adapted to the available guidelines for plant protection products has shown that no long-term adverse effects of calcium cyanamide could be observed for any of the Collembola species. Quality of the data for assessment was demonstrated by sufficiently low MDD values allowing a reliable statistical evaluation for seven species covering all life form types.

In general, ecotoxicological field studies should be considered as a valuable tool for the environmental risk assessment of fertilisers under REACH. However, as stated by ECHA [49] "Field tests are higher tier studies which provide an element of realism, but also add complexity in interpretation." To date, no clear definition of an acceptable range and duration of effects and time for recovery is given by the REACH regulation. Therefore, regulatory guidance could support both registrants and risk assessors in designing, conducting and evaluating Collembola field studies for risk assessment under the $\mathrm{REACH}$ regulation, so that this valuable data can be effectively integrated into the regulatory processes.

\section{Abbreviations}

REACH: Registration, Evaluation, Authorisation and Restriction of Chemicals; ISO: International Organization for Standardization; MDD: Minimum detectable difference; OECD: Organisation for Economic Co-operation and Development; GLP: Good Laboratory Practice; FNU: Forschungszentrum NeuUlrichstein (research center Neu-Ulrichstein); DWD: Deutscher Wetterdienst (German meteorological service); DIN: Deutsches Institut für Normung (German Institute for Standardization); NOER: No observed effect rate; USDA: US Department of Agriculture; ECHA: European Chemicals Agency; SD: Standard deviation.

\section{Acknowledgements}

We thank FNU Research Center Neu-Ulrichstein for all agricultural and logistical services. We also thank AlzChem Trostberg $\mathrm{GmbH}$ who funded the research for providing the data.

\section{Authors' contributions}

PS: conceptualization, methodology, investigation, writing original draft. JR: assessment of the study — review and editing. JS: taxonomic evaluation of samples, review of manuscript. PE: conceptualization, funding acquisition, resources, review and editing. All authors read and approved the final manuscript.

\section{Funding}

The field study was financed by AlzChem Trostberg GmbH, 83308 Trostberg, Germany.

\section{Availability of data and materials}

The datasets used and/or analysed during the current study are available from the corresponding author on reasonable request.

\section{Declarations}

Ethics approval and consent to participate

Not applicable.

Consent for publication

Not applicable. 


\section{Competing interests}

The authors declare that they have no competing interests.

\section{Author details}

${ }^{1}$ Mesocosm GmbH, Forschungszentrum Neu-Ulrichstein, Neu-Ulrichstein 5 , 35315 Homberg(Ohm), Germany. ${ }^{2}$ ECT Oekotoxikologie GmbH, Böttgerstr. 2 - 14, 65439 Flörsheim, Germany. ${ }^{3}$ Institute of Ecology and Evolution \& Field Station Schapen, University of Veterinary Medicine Hannover, Bünteweg 17d 30559 Hannover, Germany.

Received: 8 July 2021 Accepted: 31 October 2021

Published online: 20 November 2021

\section{References}

1. [OECD] Organisation for Economic Co-Operation and Development (2009) Collembolan reproduction test in soil. Guideline for the testing of chemicals 232, Paris

2. Moser T, Scheffczyk A (2009) Cyanamide: Acute and reproduction toxicity to the collembolan species Folsomia candida in artificial soil. Trostberg (Germany): Alzchem Trostberg GmbH. GLP-Study report 08BL1CR

3. De Jong FMW, Bakker FM, Brown K, Jilesen CJTJ, Posthuma-Doodeman CJAM, Smit CE, Van der Steen JJM, Van Eekelen GMA (2010) Guidance for summarising and evaluating field studies with non-target arthropods. National Institute for Public Health and the Environment (RIVM), Bilthoven (The Netherlands). RIVM report number 601712006/2010.

4. Alix A, Bakker F, Barrett K, Brühl C, Coulson M, Hoy S, Jansen JP, Jepson P, Lewis G, Neumann P, Süssenbach D, Van Vliet P (eds) (2012) ESCORT 3: Linking non-target arthropod testing and risk assessment with protection goals. CRC SETAC Press, Pensacola

5. [ISO] International Organization for Standardization (2014) Soil quality Effects of pollutants on earthworms - Part 3: Guidance on the determination of effects in field situations. ISO 11268-3. Geneva (Switzerland)

6. [MAAF] Le ministère de l'Agriculture, de l'Agroalimentaire et de la Forêt (2010) Additional Report to the DAR. Risk assessment provided by the rapporteur Member State France for the existing active substance flufenoxuron upon resubmission in the framework of the accelerated procedure in accordance with Commission Regulation (EC) No 33/2008. Volume 3, Annex B, part 5, B.9. MAAF, Paris (France)

7. Seastedt TR (1984) The role of microarthropods in decomposition and mineralization processes. Ann Rev Entomol 29:25-46

8. Verhoef HA, Brussaard L (1990) Decomposition and nitrogen mineralization in natural and agroecosystems: the contribution of soil animals. Biogeochem 11:175-211

9. Teuben A, Verhoef HA (1992) Direct contribution by soil arthropods to nutrient availability through body and faecal nutrient content. Biol Fertil Soils 14:71-75

10. Filser J (2002) The role of Collembola in carbon and nitrogen cycling in soil. Pedobiologia 46:234-245

11. Heisler C, Kaiser EA (1995) Influence of agricultural traffic and crop management on collembolan and microbial biomass in arable soil. Biol Fert Soils 19:159-165

12. [DIN] German Institute for Standardization DIN EN 13739-1 (2012) Land maschinen - Ausleger- und Wurf-Mineraldüngerstreuer - Umweltschutz - Teil 1: Anforderungen; Deutsche Fassung EN 13739-1:2011. English edition: Agricultural machinery - Solid fertiliser broadcasters and full width distributors - Environmental protection - Part 1: Requirements. EN 13739-1:2011

13. [ISO] International Organization for Standardization (2011) Soil quality - Sampling of soil invertebrates Part 2: Sampling and extraction of microarthropods (Collembola and Acarina). ISO 23611-2. Geneva, Switzerland

14. Barber HS (1931) Traps for cave-inhabiting insects. J Elisha Mitchell Scient Soc 46:259-266

15. Melber A (1987) Eine verbesserte Bodenfalle. Abh Naturw Ver Bremen 40:331-332

16. Bretfeld G (1999) Synopses on Palearctic collembolan volume 2 Symphypleona. Abhandlungen und Berichte des Naturkundemuseum Görlitz 71(1):1-318

17. Fjellberg A (1980) Identification Keys to Norwegian collembola. Norsk Entomologist Forening, Norway
18. Fjellberg A (1998) The collembola of Fennoscandia and Denmark. Part I: Poduromorpha. Fauna Entomologica Scandinavica, vol 38. Brill, Leiden

19. Fjellberg A (2007) The collembola of Fennoscandia and Denmark. Part II: Entomobryomorpha and Symphypleona. Fauna Entomologica Scandinavica, vol 42. Brill, Leiden

20. Gisin H (1984) Collembolenfauna Europas. Museum d' histoire naturelle Genf

21. Hopkin SP (2007) A key to the collembola (Springtails) of Britain and Ireland. FSC Publications, Preston Montford, Shrewsbury

22. Potapov M (2001) Synopses on Palearctic collembola, Volume 3: Isotomidae. Abh Ber Naturkundemus Görlitz 73(2):1-603

23. Stach J (1960) The Apterygotan Fauna of Poland in Relation to the World Fauna of this Group of Insects. Tribe: Orchesellini. Polska Akademia Nauk, Krakau

24. Stach J (1963) The Apterygotan Fauna of Poland in Relation to the World Fauna of this Group of Insects. Tribe: Entomobryini. Polska Akademia Nauk, Krakau

25. Thibaud JM, Schulz HJ, da Gama Assalino MM (2004) Synopses on Palearctic collembola-Volume 4-Hypogastruridae. Abhandlungen und Berichte des Naturkundemuseum Görlitz 75(2):1-287

26. Zimdars B, Dunger W (1994) Synopses on Palaearctic collembola. Part I. Tullbergiinae Bagnall, 1935. Abh Ber Naturkundemus Görlitz 68:1-71

27. Williams DA (1971) A test for differences between treatment means when several dose levels are compared with a zero-dose control. Biometrics $27 \cdot 103-117$

28. Williams DA (1972) The comparison of several dose levels with a zerodose control. Biometrics 28:510-531

29. Brock TCM, Hammers-Wirtz M, Hommen U, Preuss TG, Ratte HT, Roessink 1, Strauss T, Van den Brink PJ (2015) The minimum detectable difference (MDD) and the interpretation of treatment-related effects of pesticides in experimental ecosystems. Environ Sci Pollut Res 22:1160-1174

30. Van den Brink PJ, Hattink J, Bransen F, Van Donk E, Brock TCM (2000) Impact of the fungicide carbendazim in freshwater microcosms. II. Zooplankton, primary producers and final conclusions. Aquat Toxicol 48:251-264

31. Hommen U, Veith D, Dülmer U (1994) A computer program to evaluate plankton data of freshwater field tests. In: Hill IR, Heimbach F, Leeuwangh P, Matthiessen P (eds) Freshwater field tests for hazard assessment of chemicals. Lewis Publishers, Boca Raton (Florida, United States of America), pp 503-513

32. Shapiro SS, Wilk MB (1965) An analysis of variance test for normality (complete samples). Biometrika 52:591-611

33. Levene H (1960) Robust tests for equality of variances. In: Olkin I, Ghurye SG, Hoeffding W, Madow WG, Mann HB (eds). Essays in honor of Harold hotelling. Stanford University Press, Contributions to Probability and Statistics, Palo Alto, pp 278-292

34. Brown MB, Forsythe $A B$ (1974) Robust tests for the equality of variances. J Am Stat Ass 69:364-367

35. Dunger W, Fiedler HJ (2000) Methoden der Bodenbiologie. Fischer Verlag, Jena (Germany)

36. Eijsackers H (2011) Earthworms as colonizers of natural and cultivated soi environments. Appl Soil Ecol 50:1-13

37. Emmerling C, Strunk H (2012) Active dispersal of the endo-anecic earthworm Aporrectodea longa 6191 (Ude) in an experimental box. Soil Organisms 84:491-498

38. Auclerc A, Ponge JF, Barot S, Dubs F (2009) Experimental assessment of habitat preference and dispersal ability of soil springtails. Soil Biol Biochem 41:1596-1604

39. Bengtsson G, Hedlund K, Rundgren S (1994) Food- and density-dependent dispersal: evidence from a soil collembolan. J Anim Ecol 63:513-520

40. Römbke J, Jänsch S, Roß-Nickoll M, Toschki A, Höfer H, Horak F, Russell D, Burkhardt U, Schmitt H (2012) Erfassung und Analyse des Bodenzustands im Hinblick auf die Umsetzung und Weiterentwicklung der Nationalen Biodiversitätsstrategie. UBA-Texte 33/2012. Umweltbundesamt (German Environment Agency), Berlin (Germany)

41. Salamon JA, Wissuwa J, Moder K, FrankT (2011) Effects of Medicago sativa, Taraxacum officinale and Bromus sterilis on the density and diversity of Collembola in grassy arable fallows of different age. Pedobiologia 54:63-70

42. Hopkin S (1997) Biology of the Springtails (Insecta: Collembola). Oxford University Press Inc, New York 
43. Larink O (1997) Springtails and mites: important knots in the food web of soils. In: Benckiser $\mathrm{G}$ (ed) Fauna in soil ecosystems: recycling processes, nutrient fluxes, and agricultural production. Marcel Dekker Inc, New York, pp 225-264

44. Whalen JK, Hamel C (2004) Effects of key soil organisms on nutrient dynamics in temperate agroecosystems. J Crop Improv 11:175-207

45. [EFSA] European Food Safety Authority PPR Panel (Panel on Plant Protection Products and their Residues) (2017) Scientific opinion addressing the state of the science on risk assessment of plant protection products for in-soil organisms. EFSA J 15:4690. 225

46. [EFSA] European Food Safety Authority PPR Panel (Panel on Plant Protection Products and their Residues) (2019) Technical report on the outcome of the Pesticides Peer Review Meeting on general recurring issues in ecotoxicology. EFSA supporting publication 2019:EN-1673. 117 p. https:// doi.org/10.2903/sp.efsa.2019.EN-1673

47. De Jong FMW, Van Beelen P, Smit CE, Montforts MHMM (2006) Guidance for summarizing earthworm field studies. National Institute for Public Health and the Environment (RIVM). RIVM report number 601506006/2006, Bilthoven (The Netherlands)
48. Candolfi M, Bigler F, Campbell P, Heimbach U, Schmuck R, Angeli G, Bakker F, Brown K, Carli G, Dinter A, Forti D, Forster R, Gathmann A, Hassan S, Mead-Briggs M, Melandri M, Neumann P, Pasqualini E, Powell W, Reboulet JN, Romijn K, Sechser B, Thieme T, Ufer A, Vergnet C, Vogt H (2000) Principles for regulatory testing and interpretation of semi-field and field studies with non-target arthropods. J Pest Sci 73:141-147

49. [ECHA] European Chemicals Agency (2017) Guidance on Information Requirements and Chemical Safety Assessment Chapter R.7c: Endpoint specific guidance. https://doi.org/10.2823/43472

50. European Food Safety Authority [EFSA] (2013) Panel on Plant Protection Products and their Residues Guidance on tiered risk assessment for plant protection products for aquatic organisms in edge-of-field surface waters. EFSA J 11(3290):1-268

\section{Publisher's Note}

Springer Nature remains neutral with regard to jurisdictional claims in published maps and institutional affiliations.

\section{Submit your manuscript to a SpringerOpen ${ }^{\circ}$ journal and benefit from:}

- Convenient online submission

- Rigorous peer review

- Open access: articles freely available online

- High visibility within the field

- Retaining the copyright to your article

Submit your next manuscript at $\boldsymbol{\nabla}$ springeropen.com 